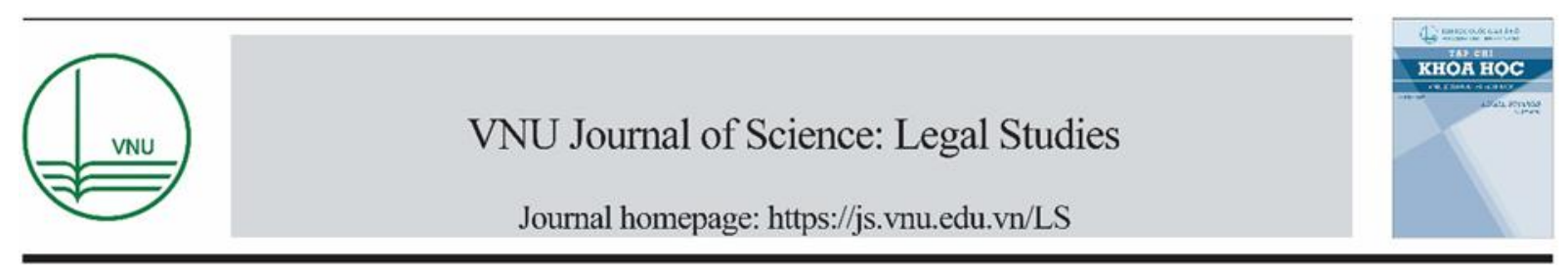

Original Article

\title{
The Position and the Development Trends of Private Property and Common Property
}

\author{
Nguyen Quang Duc* \\ Tam Anh Law Firm, 32 Hao Nam, Dong Da, Hanoi, Vietnam \\ Received 15 April 2019 \\ Revised 03 June 2019; Accepted 19 September 2019
}

\begin{abstract}
The issue of the relationship between private property and common property has engaged both legal and economic scholars in a long series of controversies over the meaning, the sequence of development, and the superiority of private vs. common property. The issues debated relate to the efficiency, equity and sustainability of private property in contrast to common property. Many scholars think of contemporary examples of common property as remnants of the past, likely to disappear during the twenty-first century. Recent research, however, has challenged the presumption that private property is necessarily superior to common property.

Keywords: Private property, common property, open access regimes.
\end{abstract}

\footnotetext{
* Corresponding author.

E-mail address: thichhocluat.vn@gmail.com
}

https://doi.org/10.25073/2588-1167/vnuls.4208 


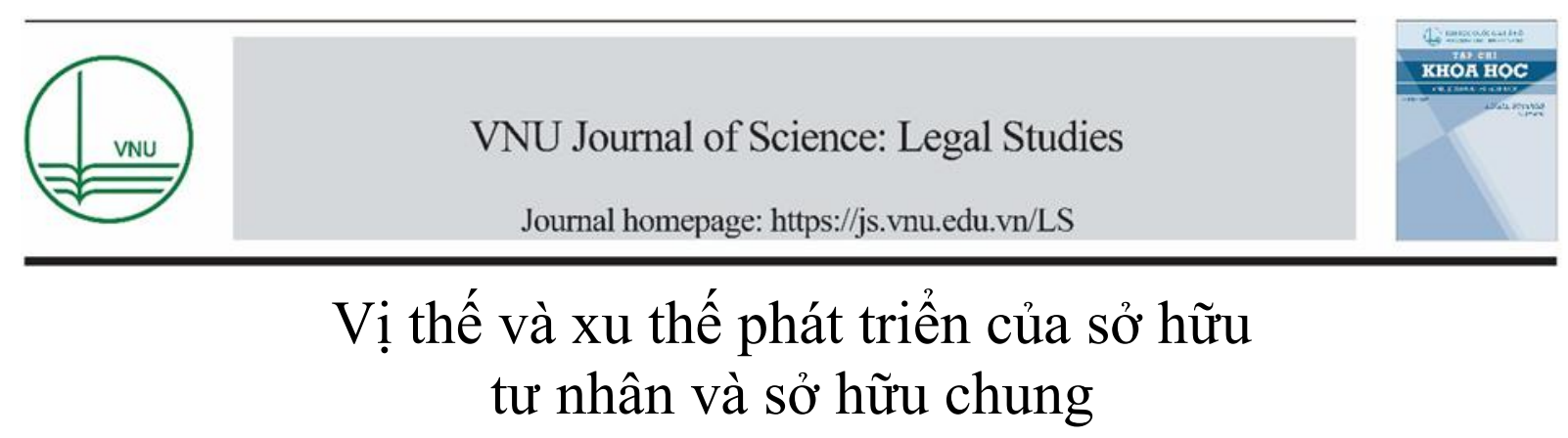

\author{
Nguyễn Quang Đức ${ }^{*}$ \\ Công ty Luật TNHH Tâm Anh, 32 Hào Nam, Đống Đa, Hà Nội, Việt Nam \\ Nhận ngày 15 tháng 4 năm 2019 \\ Chỉnh sửa ngày 03 tháng 6 năm 2019; Chấp nhận đăng ngày 19 tháng 9 năm 2019
}

\begin{abstract}
Tóm tắt: Mối quan hệ giữa sở hữu tư nhân và sở hữu chung đã thu hút cả giới nghiên cứu pháp lý và kinh tế trong một loạt các cuộc tranh luận về ý nghĩa, trình tự phát triển và tính ưu việt của sở hữu tư nhân và sở hữu chung. Các vấn đề thảo luận liên quan đến tính hiệu quả, sự công bằng và tính bền vững của sở hữu tư nhân so với sở hữu chung. Nhiều học giả nghĩ đến những thí dụ đương thời về sở hữu chung như những tàn tích của quá khứ, có thể biến mất trong thế kỷ XXI. Tuy nhiên, các nghiên cứu gần đây đã gây nên nghi ngờ liệu rằng sở hữu tư nhân nhất thiết phải có vị thế vượt trội hơn sở hữu chung.
\end{abstract}

Tù khóa: Sở hữu tư nhân, sở hữu chung, chế độ tiếp cận mở.

\section{Vị thế pháp lý của sở hữu tư nhân và sở hữu chung}

Ý nghĩa của sở hữu cá nhân so với sở hữu chung vẫn là một vấn đề tranh cãi trong pháp luật hiện đại. Trước khi cuốn sách Luật Cồ xưa (Ancient Law) của nhà luật học nổi tiếng Henry Summer Maine được xuất bản, quan điểm được chấp nhận giữa các luật gia phương Tây coi nguồn gốc của khái niệm về sở hữu trong thời cổ đại là sự chiếm đóng đất của một chủ sở hữu và gia đình của người đó [1]. Hơn nữa, tính ưu việt của sở hữu tư nhân đã được chấp nhận rộng

\footnotetext{
* Tác giả liên hệ.

Địa chi email: thichhocluat.vn@gmail.com

https://doi.org/10.25073/2588-1167/vnuls.4208
}

rãi trong các văn bản pháp luật vào đầu thế kỷ XIX khiến cho khả năng các loại tài sản khác tồn tại ở châu Âu bị đe dọa trong quan điểm pháp lý về nguồn gốc của trật tự xã hội.

Maine đã không chỉ nghiên cứu rộng rãi ở Ấn Độ mà còn khảo sát công trình của Georg Ludwig von Maurer về các cộng đồng bản địa Đức cổ, về Mark, và công trình tiên phong của William Blackstone. Maine đi đến kết luận rằng: có nhiều khả năng rằng quyền sở hữu chung mới là cơ chế thực sự cổ xưa mà không phải là quyền sở hữu riêng, và các hình thức tài sản mà cần đến sự hướng dẫn của chúng ta là những hình thức có liên quan đến quyền của các gia đình và các nhóm người theo gia đình [2: tr.252]. Tập sách đã thổi lên các tranh cãi bởi các ấn phẩm khác thách thức hoặc ủng hộ 
kết luận của ông. Cuộc tranh luận lớn hơn nhiều so với tầm quan trọng học thuật của nó, vì những cuộc đấu tranh chính trị lớn vẫn tiếp tục trong suốt thế kỷ XIX về tình trạng của nhiều dạng tài sản chung còn lại trên lục địa châu Âu. Một hệ thống lý thuyết chính trị và pháp lý đã ra đời để kiểm chứng nguồn gốc tài sản của các chủ sở hữu tư nhân. Những niềm tin này đã biện minh cho việc thông qua luật để loại bỏ quyền chiếm hữu tập thể và cho phép việc tiếp nhận tài sản chung của các chủ sở hữu tư nhân.

\section{Vị thế kinh tế của sở hữu tư nhân và sở hữu chung}

Các nhà kinh tế có khuynh hướng xem các tổ chức tài sản chung có lịch sử lâu hơn các tổ chức tư nhân và giải thích sự phát triển của các xã hội phương Tây hiện đại một phần là do thay đổi từ tài sản chung sang tài sản tư nhân $[3,4]$. Tài sản của tư nhân được hầu hết các nhà kinh tế coi là một thành phần thiết yếu trong phát triển kinh tế do những ưu đãi liên quan đến các loại quan hệ bất động sản khác nhau [5]. Thí dụ như: một nông dân sở hữu lao động, đất đai và các yếu tố đầu vào khác của chính mình, có thể sẽ thấy được mối quan hệ trực tiếp giữa các khoản đầu tư và mức lợi nhuận đạt được trong dài hạn. Một nông dân thuộc hợp tác xã sản xuất nông nghiệp, chỉ có thể thấy mối liên hệ lỏng lẻo giữa những đóng góp cá nhân và lợi ích cá nhân. Càng nhiều cá nhân trong một xã hội mà công việc của họ chỉ liên kết lỏng lẻo với lợi ích của họ thì thái độ tự do sẽ trở nên phổ biến hơn. Nếu mọi người có xu hướng coi đấy là công việc của người khác, năng suất kinh tế nói chung sẽ thấp.

Tuy nhiên, các quyền tư hữu không thể xuất hiện một cách tự nhiên từ một hệ thống sở hữu chung. Quyền sở hữu tư nhân phụ thuộc vào sự tồn tại và thực thi của một tập hợp các quy tắc quyết định ai là người có quyền tiến hành các hoạt động tự khởi tạo và cách thức phân chia các khoản thu nhập từ hoạt động đó [6]. Nói cách khác, các quy tắc và chủ thể quản lý cần phải thiết lập, theo dõi và thực thi cho một hệ thống tài sản (property system). Mặc dù một số quy tắc tạo động cơ thúc đẩy phúc lợi của hầu hết những người tham gia trong nền kinh tế nhưng luôn có những cá nhân chống lại những thay đổi do lợi ích mà họ nhận được từ một hệ thống trước hoặc đề xuất những thay đổi đặc biệt. Những chủ thể quản lý cũng có thể nhận được lợi nhuận đáng kể từ việc đưa ra các quy tắc mà có thể gây thiệt hại cho người khác.

Do đó, các chế độ sở hữu chung bị các nhà kinh tế đánh giá là kém hiệu quả do ba vấn đề. Một là, tước đoạt tiền thuê, bởi vì không ai sở hữu các sản phẩm của một nguồn tài nguyên cho đến khi chúng bị thâu tóm, và mọi người không có động lực để nắm bắt những sản phẩm này trước những người khác. Hai là, phí giao dịch và chi phí quản lý có thể sẽ tăng cao nếu chủ sở hữu trong các cộng đồng cố gắng đưa ra các quy tắc để giảm bớt những hậu quả của việc thông đồng lạm dụng. Ba là, năng suất thấp, bởi vì không ai được khuyến khích làm việc chăm chỉ để tăng lợi nhuận cá nhân [7]. Các chế độ sở hữu chung thường được giữ lại bởi các nhà cai trị không hiểu được sự gia tăng phúc lợi kinh tế tổng thể mà nền kinh tế sẽ được hưởng từ sự chuyển đổi sang tư hữu, hoặc là những người được hưởng lợi từ những chế độ "cổ xưa" này. Do đó, cách duy nhất để tránh sự đình trệ của việc sở hữu chung các nguồn tài nguyên thiên nhiên là chấm dứt hệ thống sở hữu chung bằng cách tạo ra một hệ thống quyền sở hữu tư nhân [8].

\section{Minh định sở hữu chung với chế độ tiếp cận mở}

Cuộc tranh luận về những giá trị tương đối của sở hữu tư và sở hữu chung đã bị che khuất bởi những nhầm lẫn. Các ý nghĩa khác nhau được gán cho các thuật ngữ mà không làm rõ những khía cạnh mà chúng liên quan đến nhau. Nguồn gốc của những nhầm lẫn có liên quan đển sự khác biệt giữa: (1) sở hữu chung và các chế độ tiếp cận mở (open access regimes), (2) các nguồn tài nguyên chung và các chế độ sở hữu chung và (3) hệ thống tài nguyên và các 
đơn vị tài nguyên. Cả ba vấn đề này khiến cho tính rõ ràng bị giảm đi trong việc gán nghĩa cho các thuật ngữ và làm chậm quá trình nghiên cứu lý thuyết và thực nghiệm.

\section{Sự nhầm lẫn giũ̃a sở hưu chung và chế độ tiếp cận $m o ̛$ o}

Trong một bài báo đã trở thành kinh điển, Ciriacy-Wantrup và Bishop [9: tr. 713 - 727] xác định rõ ràng sự khác biệt giữa các chế độ tiếp cận mở, nơi mà không ai có quyền hợp pháp để loại trừ bất cứ ai trong việc sử dụng tài nguyên, và sở hữu chung, nơi các thành viên của một nhóm được xác định rõ ràng có một quyền hợp pháp để loại trừ những người không phải là thành viên của nhóm đó khỏi sử dụng một nguồn tài nguyên này. Các chế độ tiếp cận mở - bao gồm các trường hợp của biển cả và khí quyển - đã được xem xét trong học thuyết pháp lý do không có giới hạn nào đối với người được quyền sử dụng tài nguyên. Nếu một người sử dụng các tài nguyên này, không ai có thể chuyển đổi quyền của họ hay đầu tư cải tiến. Nếu như một nguồn tài nguyên tạo ra sản phẩm có giá trị cao, thì việc thiếu các quy tắc liên quan đến việc sử dụng sẽ dẫn đến lạm dụng. Một số khu chăn thả gia súc ở địa phương, các bãi biển ven biển và rừng là các nguồn tiểp cận tự do và trên thực tế, chúng dễ dàng bị lạm dụng [xem thêm: 10,11].

Một số chế độ tiếp cận mở thiếu các quy tắc thiết lập các quyền tư hữu theo mặc định [12] hoặc các nguồn lực bị ảnh hưởng bởi các chế độ tiếp cận mở này không giới hạn phạm vi một quốc gia hoặc không có thực thể nào khẳng định được quyền sở hữu hợp pháp. Các chế độ tiếp cận mở khác thì là kết quả của các chính sách công cộng có ý thức để đảm bảo sự tiếp cận của tất cả người dân địa phương đối với việc sử dụng một nguồn tài nguyên theo thẩm quyền chính trị. Thí dụ: đầu thế kỷ XX, Chính phủ tiểu bang Oregon và Washington (Hoa Kỳ) đã can thiệp để ngăn chặn người dân đánh bắt cá hồi địa phương đưa ra các quy tắc hạn chế nhập cảnh và thiết lập giới hạn khai thác [13]. Các công đoàn đánh cá dọc theo các khu vực ven biển của Hoa Kỳ đã cố gắng tổ chức các trại cá ven bờ để hạn chế nhập cảnh và thiết lập các giới hạn khai thác trong những năm 1950. Mặc dù các nỗ lực của họ không có tác động nghiêm trọng đến giá cả nhờ có thị trường cá quốc tế sôi động, các công đoàn này đã bị Bộ Tư pháp Hoa Kỳ truy tố do đã vi phạm Đạo luật chống độc quyền của Sherman [14]. Do đó, các bãi đánh cá ven biển của Hoa Kỳ đã trở thành nguồn tiếp cận mở trong nhiều năm liền ở thế kỷ XX do hành động của chính phủ nhằm ngăn chặn các nhóm xây dựng địa phương thiết lập các hình thức chế độ chung trong phạm vi quyền hạn chính trị. Tuy nhiên, trong thời gian gần đây, cả chính phủ cấp quốc gia và tiểu bang đã đảo ngược vị trí của họ trước đây và tích cực tìm cách tạo ra các hình thức đồng quản lý tại các bãi biển ven bờ.

Loại hình tiếp cận mở khác là kết quả của việc các thể chế được quyền xác định sở hữu đã loại trừ một cách thiếu hiệu quả việc không có ai là chủ sở hữu. Ở nhiều nước đang phát triển, sự nhầm lẫn giữa việc tiếp cận mở và chế độ sở hữu chung mâu thuẫn nhau, dẫn đến sự gia tăng số lượng và phạm vi của các nguồn lực địa phương được phép tiếp cận mở. Hệ thống sở hữu chung kiểm soát việc tiếp cận và thu hoạch từ các nguồn suối địa phương, rừng, vùng chăn thả gia súc, và các bãi khai thác ven biển đã phát triển trong một thời gian dài ở tất cả các nơi trên thế giới, nhưng hiếm khi được đưa ra chính thức trong các quy phạm pháp luật của các nước mới được độc lập [15: tr.1061 - 1088].

Khi mối quan tâm đến việc bảo vệ các nguồn tài nguyên thiên nhiên gia tăng trong những năm 1960, nhiều nước đang phát triển đã quốc hữu quá toàn bộ những tài nguyên đất và nước mà chưa được ghi nhận là tài sản cá nhân. Các thoả thuận về thể chế mà người sử dụng ở địa phương đã lập ra nhằm hạn chế xâm nhập và sử dụng bị mất đi vị trí hợp pháp, nhưng chính phủ các quốc gia lại thiếu nhân lực và tiền của để theo dõi việc sử dụng các nguồn tài nguyên này. Do đó, các nguồn tài nguyên đang được đặt dưới chế độ sở hữu chung của những người dân địa phương được chuyển đổi sang chế độ quản lý nhà nước về sở hữu nhà nước, nhưng thực chất lại quay về với một chế độ tiếp 
cận mở. Khi các nguồn lực trước đây bị kiểm soát bởi những người dân địa phương đã được quốc hữu hoá, kiểm soát nhà nước thường tỏ ra kém hiệu quả hơn so với việc kiểm soát trực tiếp bởi các những đối tượng trực tiếp bị ảnh hưởng, nếu không muốn nói là thảm hoạ. Những tác động có hại của việc quốc hữu hoá rừng trước đây được quản lý bởi các nhóm người sử dụng địa phương đã được ghi nhận rõ ràng tại Thái Lan, Nigeria, Nepal, và Ần Độ. Các kết quả tương tự đã xảy ra đối với các bãi ven biển do các cơ quan nhà nước hoặc quốc gia nắm giữ thay vì kiểm soát của chính những ngư dân [8].

Sự nhầm lẫn giũua một nguồn tài nguyên chung và một chế độ sở hũu chung

Các vấn đề phát sinh từ các nhầm lẫn giữa chế độ tiếp cận mở với các sở hữu chung khó có thể vượt qua được do vấn đề thuật ngữ thứ phát. Thuật ngữ "tài sản chung" thường được sử dụng để mô tả một loại hàng hóa kinh tế mà có thể được gọi chính xác hơn là "tài nguyên chung”. Tất cả các tài nguyên chung đều chia sẻ hai thuộc tính quan trọng đối với các hoạt động kinh tế: (1) tốn kém để loại trừ cá nhân khỏi sử dụng hàng hoá dù là thông qua việc sử dụng các rào cản vật lý hay qua các văn bản pháp luật và (2) lợi ích của một cá nhân phải trừ đi từ những lợi ích có sẵn cho người khác [16: tr.157-172;17]. Nhận biết được loại hàng hoá chia sẻ hai thuộc tính này cho phép các học giả xác định được các vấn đề lý thuyết cốt lõi đối với một cá nhân bất cứ khi nào có nhiều cá nhân hoặc nhóm sử dụng các nguồn tài nguyên đó trong một khoảng thời gian dài.

Các nguồn tài nguyên chung có cùng khó khăn với hàng hoá công trong việc loại ra các bên có lợi về mặt vật chất lẫn mặt thể chế. Trừ khi có các công cụ không cho phép những người không có quyền được phép hưởng lợi, sự cám dỗ mạnh mẽ của việc hưởng lợi trên nỗ lực của người khác sẽ dẫn đến sự đầu tư hơn nữa trong việc cải thiện tài nguyên, theo dõi việc sử dụng và xử phạt hành vi vi phạm pháp luật. Thứ hai, các sản phẩm hoặc thành phần của các nguồn tài nguyên chung có chung thuộc tính về việc sự tiêu thụ của một người sẽ làm giảm đi số lượng còn lại cho những người khác, giống với hàng hoá tư nhân. Do đó, các nguồn tài nguyên chung có thể bị các vấn đề như cản trở, sử dụng quá mức và phá hủy tiềm năng trừ khi có những hạn chế khai thác hoặc sử dụng được xây dựng và thực thi. Ngoài việc chia sẻ hai thuộc tính này, tài nguyên chung rất khác so với tài sản chung về nhiều thuộc tính khác bao gồm bao gồm kích thước, hình dạng và năng suất và giá trị, thời gian và sự đều đặn của các đơn vị nguồn lực.

Các nguồn tài nguyên chung có thể thuộc sở hữu của các chính phủ quốc gia, khu vực hoặc địa phương; bởi các nhóm cộng đồng; bởi cá nhân hoặc công ty tư nhân; hoặc được sử dụng như là nguồn tiếp cận mở của bất cứ ai có thể được tiếp cận. Mỗi loại cơ chế sở hữu (có tính chất) rộng rãi có những ưu điểm và bất lợi khác nhau, tuy nhiên đôi khi có thể dựa vào các quy tắc hoạt động tương tự liên quan đến việc tiếp cận và sử dụng một nguồn tài nguyên [18]. Đã có những tiền lệ chứng minh là việc quản lý và bảo đảm các nguồn tài nguyên chung của các chính phủ, các nhóm cộng đồng, hợp tác xã, hiệp hội tự nguyện, và các cá nhân hoặc doanh nghiệp tư nhân có thể thành công hoặc không $[19 ; 20 ; 21]$. Do đó, không có sự kết hợp tự động của các tài nguyên chung với các chế độ sở hữu chung hoặc, với bất kỳ loại quy chế bất động sản cụ thể nào khác. Hơn nữa, các thỏa thuận sở hữu chung về cơ bản là hợp đồng chia sẻ, và như vậy, cũng phải đối mặt với những khó khăn tương tự về hành vi cơ hội và những vấn đề nguy hiểm về đạo đức.

Sự nhầm lẫn giữa hệ thống tài nguyên và dòng chảy của các đơn vị tài nguyên

Nguồn tài nguyên chung bao gồm các hệ thống tài nguyên và các đơn vị (thuộc hệ thống) tài nguyên hoặc lợi ích có được từ các hệ thống này [22]. Hệ thống tài nguyên (hoặc cách khác, cổ phiếu hoặc cơ sở vật chất) là những gì tạo ra một dòng chảy của các đơn vị tài nguyên hoặc 
lợi ích theo thời gian [23: tr.393 - 436]. Thí dụ về các hệ thống tài nguyên thông thường chung chung bao gồm hồ, sông, hệ thống thủy lợi, lưu vực nước ngầm, rừng, các kho dự trữ và khu chăn thả. Nguồn tài nguyên chung cũng có thể là các cơ sở vật chất được xây dựng để sử dụng chung, chẳng hạn như máy tính lớn và Internet. Các đơn vị tài nguyên hoặc lợi ích từ nguồn tài nguyên chung bao gồm nước, gỗ, cây thuốc, cá, thức ăn gia súc, các đơn vị chế biến trung tâm, và thời gian kêt nối. Thiết lập các cơ chế về sở hữu tài sản cho phép sử dụng bền vững nguồn tài nguyên chung đòi hỏi phải có các quy tắc hạn chế việc truy cập vào hệ thống tài nguyên và các quy tắc hạn chế số lượng, thời gian và công nghệ được sử dụng để thu hồi các đơn vị tài nguyên đa dạng từ hệ thống nguồn lực.

\section{Xu thế kết hợp của sở hữu tư nhân và sở hữu chung trong thế kỷ 21}

Trọng tâm tập trung vào các nguồn tài nguyên thiên nhiên, tuy nhiên, nhiều bài học rút ra từ hoạt động của các chế độ sở hữu nhà ở trong các lĩnh vực này khá phù hợp với sự đa dạng của các chế độ sở hữu tương tự đang được sử dụng rộng rãi và có khả năng có một sự hiện diện đáng kể trong thế kỷ tiếp theo. Một số lượng lớn các dự án phát triển nhà ở - cả nhà chung cư và nhà riêng của gia đình - sử dụng tài sản của cá nhân để kết hợp với tài sản cộng đồng để tạo ra các sân chơi, phương tiện giải trí và các cơ sở vật chất chung khác. Trong khi cá nhân có thể mua và bán các đơn vị nhà ở riêng lẻ của họ, tại thời điểm mua hàng, họ nhận các nghĩa vụ liên quan đến các tài sản chung liên quan chặt chẽ. Việc mua và bán thường đòi hỏi sự cho phép của các thành viên khác trong nhóm. Tương tự như vậy, nhiều câu lạc bộ thể thao sử dụng hạn ngạch cho các thành viên và đánh giá các khoản phí thường xuyên của thành viên để duy trì các cơ sở được sở hữu.

Công ty hiện đại thường được coi là mẫu mực của tài sản cá nhân. Trong khi mua và bán cổ phần của cổ phiếu công ty là một ví dụ rõ ràng về quyền phân biệt đối xử trong công việc, các mối quan hệ trong phạm vi công ty lại không phải là quyền sở hữu cá nhân. Do thu nhập sẽ được chia sẻ giữa các cổ đông, người quản lý và nhân viên là một phần chung để chia sẻ, tất cả các ưu đãi dẫn tới việc lẩn tránh trách nhiệm và lạm dụng được tìm thấy trong cấu trúc của một tập đoàn hiện đại [xem thêm: $24 ; 25$; 26]. Do đó, trong thế kỷ tới, nơi mà chúng ta sống, làm việc có xu hướng được quản lý bởi một hệ thống hỗn hợp về quyền sở hữu chung và cá nhân.

\section{Tài liệu tham khảo}

[1] Grossi, Paolo, An Alternative to Private Property; Collective Property in the Juridical Consciousness of the Nineteenth Century, Chicago: University of Chicago Press, 1981.

[2] Maine, Henry Sumner, Ancient Law: Its Connection with the Early History of Society and its Relation to Modern Ideas; With Introduction and Notes by Frederick Pollack, Boston: Beacon Press (reprint of 1861 ed.), 1963 , p. 252.

[3] North, Douglass C. and Robert Paul Thomas, The Rise of the Western World: A New Economic History, London: Cambridge University Press, 1976.

[4] North, C. Douglass, L. Terry Anderson, and J. Peter Hill, Growth and Welfare in the American Past: A New Economic History, Englewood Cliffs, NJ: Prentice-Hall, 1983.

[5] W.P. Welch, The political feasibility of full ownership property rights: The cases of pollution and fisheries, Policy Sciences, 16, (1983) 165-80.

[6] Ostrom, Vincent, The Intellectual Crisis in American Public Administration, 3rd ed., Tuscaloosa: University of Alabama Press, 2008.

[7] North, C. Douglass, Institutions, Institutional Change, and Economic Performance, New York: Cambridge University Press, 1990.

[8] Elinor Ostrom and Charlotte Hess, Private and Common Property Rights, Workshop in Political Theory and Policy Analysis, Indiana University, 29/11/2007,

https://surface.syr.edu/cgi/viewcontent.cgi?artic $l e=1024 \&$ context $=$ sul (truy cập lần cuối: 31/03/2019).

[9] Ciriacy-Wantrup, V. Siegfriedand, C. Richard Bishop, Common property as a concept in 
natural resource policy, Natural Resources Journal, 15, 1975, 713-727.

[10] Báo Pháp luật (điện tử): https://plo.vn/thoisu/dai-bieu-lo-dan-het-duoc-tu-do-tam-bien-ophu-quoc-774398.html (truy cập lần cuối: 05/04/2019).

[11] Báo Tuổi Trẻ (điện tử): https://tuoitre.vn/khong-the-chap-nhan-tinhtrang-lay-bien-lam-cua-rieng2018110711421466.htm (truy cập lần cuối 05/04/2019.

[12] Dales, H. John, Pollution, Property, and Prices: An Essay in Policy-Making and Economics, Toronto: University of Toronto Press, 1968.

[13] Higgs, Robert, Legally induced technical regress in the Washington salmon fishery, in L. J. Alston, Thráinn Eggertsson, and Douglass North (eds), Empirical Studies in Institutional Change, New York: Cambridge University Press, 1996.

[14] Johnson, N. Ronald and D. Gary Libecap, Contracting problems and regulation: The case of the fishery, American Economic Review, 72 (1982) 1005-1022.

[15] Wiersma, L. Lindsey, Indigenous lands as cultural property: A new approach to indigenous land claims, Duke Law Journal, 54 (2005) 1061-1088.

[16] Ostrom, Vincent and Elinor Ostrom, A theory for institutional analysis of common pool problems, in Garrett Hardin and John Baden (eds), Managing the Commons, San Francisco, CA: W. H. Freeman, 1977, p. 157-172.

[17] Ostrom, Elinor, Roy Gardner, and James M. Walker, Rules, Games, and Common-Pool
Resources, Ann Arbor: University of Michigan Press, 1994.

[18] Feeny, David, Fikret Berkes, Bonnie J. McCay, and James M. Acheson, The tragedy of the commons: Twenty-two years later, Human Ecology, 18 (1990) 1-19.

[19] Bromley, W. Daniel, The commons, common property, and environmental policy, 2 Environmental and Resource Economics (1992) 1-17.

[20] Singh, Katar, Managing Common Pool Resources: Principles and Case Studies, New Delhi: Oxford University Press, 1994.

[21] Singh, Katar and Vishwa Ballabh, Cooperative Management of Natural Resources, New Delhi: Sage, 1996.

[22] Blomquist, William and Elinor Ostrom Institutional capacity and the resolution of a commons dilemma, Policy Studies Review, 5 (1985) 383-393.

[23] Lueck, Dean, The rule of first possession and the design of the law, Journal of Law and Economics, 38 (1995) 393-436.

[24] Ghoshal, Sumantra and Peter Moran, Bad for practice: A critique of the transaction cost theory, Academy of Management Review, 21 (1996) 13-47.

[25] Putterman, Louis, Markets, hierarchies, and information: On a paradox in the economics of organization, Journal of Economic Behavior and Organization, 26 (1995) 373-390.

[26] Seabright, Paul, Managing local commons: Theoretical issues in incentive design, Journal of Economic Perspectives, 7 (1993) 113-134. 